The Geneva Papers on Risk and Insurance, 21 (No. 80, July 1996), 324-335

\title{
The EU Experience and the Challenges in Insuring Environmental Risks*
}

\author{
by Dr. Jürg Spühler**
}

\section{The present situation}

\subsection{The present situation in the industrialized world}

Each and every economic activity - whatever its level of technological sophistication, its nature of objective envisaged and its kind of promoter - cannot avoid emissions of harmful substances which impair the natural resources (air, soil and water) and henceforth the environment. Some impact resulting thereof is of temporary kind only as 'nature' is in the position to cope with it at about the same pace and with the same intensity as it is incurring. However, in many instances the impairment is of long-term character thereby changing the original state of the 'free goods' in an embracing and fundamental way for many years.

Specific characteristics attached to environmental impairment render their assessment as to existence, source, extent and magnitude extremely difficult. In many instances the impairment is of gradual, insidious nature and its origin is largely unnoticed over long periods of time. The many scenarios encountered today with abandoned waste disposal sites and former working places of the producing industry illustrate this situation in a very drastic manner. It is not Seveso, Bhopal and Schweizerhalle which set the tone of such hardship though the consequences for the environment have been disastrous as well there.

Within this general scenario the question of environmental sustainability moves more and more into the centre of fierce discussions held within and between industry, govern-

\footnotetext{
* Paper from the Workshop on Management Strategies for Eco-Efficiency and Cooperation, Stuttgart, May 24 - 25, 1995.

**Member of Senior Management, Swiss Reinsurance Company, Zurich.
} 
ment, green movements and the public. Thereby three decisive aspects have to be taken into account: the technical, the social and the legal aspects. All of them are tightly linked together, influence each other in a deep-rooted way and present themselves as a cobweb fragile and multidimensional!

The technological advancements - primarily since the early $50 \mathrm{~s}$ - have brought about an exposure to nature and mankind on an extremely high level and in a rather extensive manner. Sophisticated production processes and numerous 'artificial' raw materials applied in all sectors of the economy as well as the global dimension in the trading of the products manufactured create a world-wide impact on the environment. It is, therefore, not surprising that the general Products Safety Directive recently enforced by the European Union is based on the manufacturer's responsibility for his goods and services produced and sold from their 'cradle to the grave' - from their first-stage design until their final disposal.

In line with the technological advancements an increasing sensitivity of the public in respect of environmental issues can be observed - foremost in the industrialized countries. Manufacturers and traders are 'on the watch list' of everybody and exposed to the instant 'on the spot' disclosure of incidents by the media. The propensity to claim for compensation if damage or injury occurred is steadily increasing. Thus the social aspect must be taken into account on a far wider scale than hitherto.

As a response to the technological and social situations being present more onerous legal rules have come into force for quite a number of years now. Such legislation focuses technical and behavioral aspects, enlarges penal codes and introduces stricter legal liability rules for all segments of industry and trade to a very substantial degree. On the one hand the interference into economic activities is embracing and of deep impact on the decision process of the entrepreneur; on the other hand the positive result on the environment is not demonstrated - at least not yet for the time being.

Therefore, there is the fundamental question which now arises and faces today's society:

Where do we go from here - shall we quit the experience of the busy legal machinery or shall we pick up the challenge attached to it?

\subsection{The present situation in the European Union}

From a world-wide view, the diverse national legal enactments developed into a patchwork of rules and regulations. They are far from constituting a streamlined and wellbalanced system.

The very same unsatisfactory situation has also been generated within the European Union: since the incident in Seveso numerous technical and behavioral regulations have been enacted which have risen the liability exposure for industry and trade. Up to now no specific civil liability rules applicable for environmental impairment have been enacted by the European Union. During the past few years two Directives (one on Civil Liability for Damage caused by Waste and the other on Civil Liability for Landfills) have been drawn up However, they have not been enforced yet. It has been realized that these Directives 
are focusing only partial aspects of the environmental problems and that they link themselves into the economic cycle of goods and services in its very last phase only. Both Directives would have enlarged the patchwork already being in place - instead of enforcing a system of rules really solving the core problems of the general environmental issue faced today.

As a logical consequence of this unsatisfactory situation the Commission of the European Union issued in May 1993 the Green Paper on Remedying Environmental Damage. This Paper establishes a basic platform by discussing the major problem areas and - from the European Union's point of view - by outlining within alternative solutions the most likely direction of the appropriate way to go in future. At the same time a framework for a fundamental system on the basis of a twin approach to the environmental problem is suggested:

first, a community-wide civil liability system is to be created which requires the party damaging the environment to rectify the damage caused, and

second, a complementing collective compensation system is to be implemented taking care of those cases where no identifiable party can be held responsible for environmental damage caused.

To the first approach the principle of prevention and the polluter pays principle are attached. They channel the focus on the party having the expertise, the resources and the operational control to accomplish the most effective and the most economical risk management in respect of environmental impairment exposure.

The second approach complements the first in so far as it creates a system where the ordinary civil liability system fails to impose the duty of the individual wrongdoer to compensate the party having suffered injury or damage. This part of the system is based on a specific kind of social principle.

Finally, it must be added that the approach outlined is governed by the principle of subsidiarity which has been generally introduced by the Maastricht Treaty. In this context subsidiarity entails justice being done to the autonomy of the individual Member State where it is considered as feasible. This over-all principle expresses the intention of the European Union to regulate only where it is absolutely necessary and where at the national level no or only inadequate rules are in place. This principle may somewhat quiet down the rather busy European legislation machinery. But what it will mean in real terms is still an open question today.

Presumably the proposal for a EU Directive on Environmental Impairment Liability will be published in 1996. Discussions in late spring of 1995 disclose that the main focus within the generally applicable Directive will be set to future environmental impairment rather than that having been put into place in the past. The latter would most probably rather be left to legislation and ordinances established on an individual basis by the Member States. What the general tenor of the Directive is concerned two main approaches seem to be open now: either it provides a comprehensive framework stretching all over the EU or it fills in only the gap being present in national legislation up to a specific level defined therein. 


\subsection{The fundamental situation of the liability insurer}

The liability insurer finds himself in a rather uneasy and highly complex situation what environmental liability insurance is concerned. This situation predominantly originates from two distinct sides:

first, from the unique qualities attached to the sources of environmental impairment and their negative consequences on the ecology, the people and their property,

second, from the legislation governing environmental impairment liability as well as the judgements resulting thereof.

Harmful substances and materials - not necessarily of large quantity - are in the position to cause huge injury or damage to a large number of individuals and enterprises within an extremely vast geographical area. The loss scenarios encountered may result from accidental incidents as well as from happenings occurring gradually and over an extremely long period without being detected in time to take appropriate countermeasures. Very often only new technologies enable the definition, the discovery and the tracing of impairing 'leaks' and allocating the impairing effects to specific substances, materials and processes - most of them having been regarded as harmless formerly. Specifically the long-term element involved enables, in the course of time, the unnoticed spreading of impairing effects over immense areas and enforces a striking negative impact on a large number of people.

The unique qualities attached to the sources of environmental impairment create a high degree of uncertainty as to the extent of risk (likelihood of the happening of an impairing event and the monetary impact of such an event) being in place. For the liability insurance underwriter such a situation is highly undesirable as he is at a loss to assess and henceforth to rate the environmental risk properly and to design an appropriate insurance cover engaging him in line with his financial standing - thereby observing the insurer's fundamental state-of-the-art principle always to limit his obligations in time and in amount as his financial resources are monetary-wise limited. This constitutes the primary reason why within environmental impairment liability insurance experience rating has become outdated and replaced by quite sophisticated exposure rating techniques.

In addition, the on-going, abrupt and unforeseeable changes in legal liability rules and judgements based upon them as well as the repeated judicial re-writing of policy wordings create a highly uncertain and aggravated risk situation for the underwriter. The impact of legislation and judgements on insurance has been very dramatic during the past two decades. The situation faced by the underwriter is determined by the extension of strict legal liability norms to the impairment of all three 'free goods' (water, soil and air), the allowance of only a very few exoneration reasons relieving the party focused on, the introduction of presumed liability (as for example in the German Environmental Impairment Liability Act enforced as per January 1, 1991) and the undue application of the principle of joint and several liability (as demonstrated by the US Superfund Legislation). In some of the jurisdictions the situation has been aggravated by the fact that the stringent legal rules and regulations have been declared as applicable to events and happenings - whether detected yet or not - caused prior to their enactment thus generating retroactive civil liability (as for example by the US Superfund Legislation). This legal set- 
up triggered that part of the liability policy portfolio of the insurance carriers which lapsed long ago what brought about an unexpected and a most adverse financial impact on the insurance industry whose negative final effects can only be defined in very broad terms.

\section{The future situation in the European Union}

\subsection{The Green Paper as basic platform}

The Green Paper discloses that the European Union is on its way likely to create a framework for an embracing compensation system. This framework is to be filled in by a number of harmonized Directives and other enactments applicable to a wide range of economic activities to replace the present patchwork.

The European Commission has provoked an embracing and intensive public debate on environmental impairment and its compensation by the wrongdoers. The different positions taken by governments, industrial and trade associations, insurance associations, political parties and specific interest groups vary considerably and disclose the existing wide gaps in their attitude, interest and objective what environmental impairment and the legislation applying thereto is concerned.

In principle, the compensation system focused on by the European Union consists of two different parts which complement each other, namely of

- a strict civil liability regime on the one hand and

- a joint or collective compensation system embodied in a specific fund on the other hand.

\subsection{The basic scenario}

\subsubsection{Civil liability system}

The key elements on which the envisaged civil liability system most likely is to be based are found in a strict liability norm (replacing tort liability), the principle of joint and several liability (enhancing the deep-pocket-approach) and a very limited number of exoneration reasons (tightening most of the loop-wholes to escape liability).

The trend to be observed within judgements by the courts during the past few years demonstrates clearly that the existing tort liability rules more and more were remodeled. Negligence is affirmed at a far lower level than originally intended by the legislators enacting tort liability rules, or the presence of the burden of proof imposed on the plaintiff is affirmed rather quickly in order to establish tort liability, or the causal relationship is considered as being adequate within wider boundaries than formerly. All this has turned the tort system - what its final result is concerned - to a quasi strict liability system in favor of the party claiming for compensation in respect of injury or damage suffered from environmental impairment. Thus the formal incorporation of strict liability in modified or new laws to replace tort liability will in fact not dramatically result in more numerous verdicts or bring about real heavier burdens on the defendant's shoulder. However, this liability regime must have some clearly defined, practicable and adequate means for defense, at the minimum, with regard to the victim's fault, the events caused by 'force majeur', the 
actions committed by third parties and the development risk (state-of-the-art of technology).

Contrary to the position taken by officials of the European Union it is - according to numerous discussions within government, industry, trade and insurance - an open question whether the strict liability system envisaged would in fact provide a real incentive for the entrepreneurs to take extensive preventive technical, operational and organizational measures in respect of environmental damage.

The possibility to apply the principle of joint and several liability is of deeper concern on the underwriter's side, foremost if enforced in its strictest sense. It is not justified to present the whole bill for compensation to a polluter having contributed to the environmental impairment only in a minor way just because of his financial abilities to pay for it and to let the major polluter off the hook in view of his bankruptcy status - leaving them among themselves to arrange for the justified and pollution-related split up of the loss. The joint and several liability regime truly encourages the 'deep-pocket-approach' and therefore prompts costly law suits as the American experience has repeatedly demonstrated. Under this view a proportional liability scheme based on the real share of contribution to the environmental impairment and its consequences appears to be closer to a 'just' and economical civil liability system.

\subsubsection{Joint or collective compensation system}

The civil liability system constitutes only part of a 'full range' compensation system for injury or damage resulting from environmental impairment. By nature it fails to secure compensation in the following cases:

first, for chronic pollution, this is for the cumulative impacts originating from the activities of a multiple of private and commercial entities, where the allocation of a specific source - based on the adequate causal relationship between a specific source or cause of emission and the place where harm occurred - to an individual party fails. Here we face the so-called long-distance and incremental damage,

second, for pollution resulting from emissions being allowed by the competent authorities within normal, undisrupted operational activities, this is where the imposition of legal liability is questionable as the feature of illegality and excessiveness is not in place (however, in Germany such impairment falls under the strict legal liability norm introduced by the Environmental Impairment Liability Act in force since January 1, 1991),

third, for pollution being already in place as a result of former activities of private and commercial entities, this is where the causal link between the origin of emission and the loss or damage cannot be really established any longer, and

finally, for pollution where - though the liable party can be identified - the indemnity is statute-barred pursuant to the applicable legislation.

In view of these areas a system complementing the civil liability system must be put into place. The Green Paper suggests to accomplish this objective by introducing a Joint or Collective Compensation System. Such system is to be embodied in a Collective Indemnity Fund. 
What are the basic requirements which must be attached to such a System or Fund? In summary, the very same fundamental principles must be present as those attached to the traditional individual system of compensation for injury or damage. This means that any collective indemnity system or fund must be sustainable with a view to the whole setup of the economic, social and political system in which they are to be integrated. Sustainability and compatibility is present, if they do not jeopardize the established and well-proved rules and principles of the traditional compensation system. Furthermore, they are only acceptable if their mechanics and their range of application is clearly defined and strictly focusing distinct and concrete situations. This means that the claimants eligible for compensation and the compensation being claimable by them must be clearly defined as to its kind and monetary extent. This is the most fundamental prerequisite - otherwise the monetary costs attached to such a system are not calculable in advance. Such calculability must, however, be present as the monetary means to be spent must be part of a governmental budget or part of the entrepreneurial calculation within the budgets of the kind of business obliged to contribute to such a fund.

In this respect it must be observed that collective funds and systems do not only focus the legal entity eligible for compensation but also the group which must financially contribute to the fund. Thus, there is the vital question of finding the relevant criteria for defining the adequate group of contributors. Should those belonging in whole or in part to the group being eligible for compensation also belong to the group of contributors? Or, must there be a strict separation between beneficiaries and contributors?

The fund or system must, finally, be designed in line with the principle of economic behavior: they must outweigh their economic and social costs generated by themselves.

They are, under no circumstances, allowed to take the role of a 'super social compensation system'!

To summarize, any acceptable collective indemnity funds and systems are by far not simpler in kind and set-up than individual compensation systems (including those established by the means of insurance) being already in place. Therefore, they cannot be favored as such or even taken as a substitute of the latter. The fundamental question is not 'individual compensation system embodied in the legal liability rules and principles' versus 'collective compensation funds or systems', but the establishment of a prudent complement to the individual system by an adequate, specifically designed and flexible collective system.

\section{The central problem of insurability}

\subsection{The fundamental task of the liability insurer}

Within the existing scenery composed of the legal, technical and social aspects the liability insurer strives to perform a dual task, namely

first, he aims - in the context of an added value task - at preventing and limiting recognized and assessed risk situations threatening the due performance of economic entrepreneurial activities, and 
second, he transfers - in the context of his traditional task - the negative financial consequences of realized risks away from the entrepreneur as wrongdoer and responsible party.

This fundamental tasks-related situation is also present in respect of environmental impairment liability and its insurance. Here however, a number of traditional prerequisites rendering risk scenarios and their financial consequences as transferable to the insurer as such are not existing. The reason for this situation is found in the fact that specific characteristics are attached to environmental risks as outlined above. They render their assessment as to existence, source, extent and possible impact as rather difficult.

Apart from the technological peculiarities limiting insurability of environmental liability risks, there is the legal aspect which creates a fundamental problem as to insurability.

Presently, the Green Paper still leaves it open whether - from the insurance industry's point of view - the future situation under the legal aspect is to become an attractive challenge and therefore an opportunity or a shuddering nightmare. It is left to the authorities in Brussels whether the still-to-be-defined details of the environmental liability Directive respond to the fundamental requirements of insurability.

If the responsible bodies abstain from observing these requirements, any enlarged legal framework within the European Union does not make any sense. It would do great harm to entrepreneurial activities and the technological progress within such activities and it would do great harm to the present functioning of the insurance industry as one of the major financial guarantors for any economic performance and development.

\subsection{The impact of legislation on liability insurance}

Within the highly sensitive field of environmental impairment liability insurance the legislator has to observe rather definite boundaries which are not to be trespassed without creating a severely adverse effect upon the availability of insurance protection. Emotionally and politically charged principles and rules should not constitute the guideline for introducing fundamental changes with a newly designed environmental liability system.

First, it is wrong to assume that the introduction of a compulsory insurance regime would enlarge opportunities for the entrepreneur to transfer the consequences of environmental liability risks to the insurer on better terms and conditions than today. If the legislator intends to fix parameters like minimum extent of coverage to be provided (including trigger of coverage and aggregation of compensation payments within a single insurance period) and minimum limit to be insured, the situation would likely become more adverse than that encountered on the present world insurance market in respect of placing (high exposed) environmental liability risks. It must be noted that the insurance industry wants to develop this type of insurance cover at its own pace, along commercially and technically sound principles. The lability insurance underwriter does not want to be placed in the role of an environmental policeman within the process of assessing the risks to be covered and the qualification as to their acceptability, thereby in fact deciding who is allowed to continue to do business and who not. This is a task which has exclusively to be 
performed by the governmental authorities.

Second, what the set-up of the civil liability regime is concerned the following aspects are to be observed by the legislator:

- no liability is to attach to emissions allowed by the competent authorities as well as to those emissions not resulting from negligent behaviour of the causing party - also if at a later point of time stricter technical rules are introduced outlawing the former levels having been tolerated,

- no liability is to attach to ecological damage, this is damage to the 'unowned' environment (such damage has to be compensated by other ways and means than civil liability rules and should be dealt with by Public Law),

- no liability is to attach to long-distance and incremental damage,

- no liability is to attach in accordance with new (and most probably stricter) liability norms to environmental impairment caused prior to the introduction of such new norms. The retroactive application of stricter compensation rules within legal liability norms in respect of actions which were neither negligent nor unlawful at the time they were undertaken is beyond any acceptable standard,

- no liability is to attach to first party losses under liability insurance covers, except for costs resulting from loss prevention measures to avert or minimize an imminent and unexpected third party loss,

- joint and several liability rules should not apply for parties which are only involved to a minor extent in environmental pollution in order to prevent the adverse effects of deeppocket situations.

Finally, the legislator must observe that the determination of the structure and cover of an environmental impairment liability policy must be left to the discretion of the underwriter. Long-tail liabilities require the application of specific insurance techniques - like for example the use of the claims-made or the manifestation basis to trigger the insurance coverage. Any legislation or judgement rendering policies unenforceable because they are of such a type would prompt insurers to abstain from providing adequate insurance protection.

What a joint compensation system is concerned the legislator must observe that such a system is designed in a manner which is not competing with the insurance market and which does not prevent any developments of new insurance products.

\section{Outlook}

\subsection{The role of the liability insurer}

Within his dual task - prevention and reduction of risks as well as transfer of negative consequences resulting from risks - the liability insurer takes a very active role within the realization of risk management strategies of the entrepreneurs. He introduces his experience gained from claims settlements and his expertise acquired through assessments of environmental risks presented to him for insurance coverage. 
The loss prevention and loss reduction focus on constructional modifications of equipment and plants, process-related alterations, substance-related substitutions and organizational improvements. For example, the mere reduction in the stock of harmful material and substances may invoke a substantial reduction in the environmental exposure of a production site which outweighs the increase of such exposure brought about by the increase in the number of transportations of the very same kind of material to the site. Or, the replacement of lagoons on the site for evaporation of liquid residues by the introduction to an appropriate water treatment plant could substantially improve the risk situation in place. The same effect may result from the floor sealing of those areas where liquid harmful substances are loaded and unloaded in order to prevent the penetration of the spillages into the soil. Also the capping of air emissions within production halls and their purification by filters prior to introduction of in-door air into the atmosphere often results in a reduction of environmental impairment exposure.

Leading industrial insurers and reinsurers have established specific units (risk management or risk engineer sections) within their organizations to support their clients in environmental impairment matters. It has been recognized that any claims payments do never outweigh the real economic loss resulting from pollution events. Any impairment of the environment always reduces the scarce natural resources and irreversible destroy part of nature, damage private property or result in injuries of people.

In short, it is the insurer's task to disclose to the entrepreneur his own expertise and to support him on an ongoing basis what the development in the field of environmental impairment in respect of the technological, social and legal aspects are concerned.

\subsection{The role of the entrepreneur}

Quite a few entrepreneurs, as a rule, feel - unfortunately! - safe with their behaviour, especially if they have never been involved with an environmental impairment liability case. The same situation is encountered here as in other risk areas: 'on my site there was never a fire and my fire alarm, smoke detector and sprinkler system are in place - thus, no fire will really ever hit my existence in future as well!'

Such an attitude must be qualified as very risky. Instead, the entrepreneur should establish a risk strategy and base upon it specific safety measures - among them a specific insurance program focusing the environmental impairment liability exposure. An extensive dialogue with the insurer is necessary to accomplish the appropriate risk transfer by the means of insurance. In order to secure an updated insurance program it must be kept in line with the ongoing changes in the entrepreneur's activities and site situations. The complexer the legal rules and the stricter the liability norms the more important is the tight link between entrepreneur and underwriter. And for the underwriter the task to provide updated and embracing support in the distinct field of environmental impairment liability constitutes an outstanding challenge in performing his professional activities.

Therefore, it is of vital importance that the entrepreneur discloses to the insurer at all times the many changing situations taking place at his site and to report on incidents which may have an environmental impact. 


\subsection{The role of the legislator}

The impact on insurance - foremost on environmental impairment liability insurance - has been dramatic since the early $80 \mathrm{~s}$. The most significant features to be mentioned within this context are the following: the extension of strict legal liability rules, the allowance of only a very few exoneration reasons for the wrongdoer, the introduction of 'presumed' liability, the stipulation of liability for undisrupted normal operations and the undue application of the principle of joint and several lialbility.

These features have slowed down the engagement of the environmental liability insurer whereas the need for the entrepreneur to acquire adequate insurance protection for the environmental risks developed into the opposite direction.

It is the task of the legislators to stop this process and to reverse the tendencies mentioned by abstaining from the enforcement of modified or new laws of the kind and nature referred to above. The European insurance market now at the promising start of the area of liberalization and deregulation must not be kept back by a liability system which renders environmental liability risks as uninsurable. On the contrary, the legislators must provide for a stable framework within liberal boundaries not turning the civil liability system eventually complemented by a collective joint compensation system - into a super social system where there is no room left for the urgently needed liberal market.

Furthermore, it must be noted that the introduction of legal rules to enforce an extensive system of compulsory insurance stretching over the whole European Union without regard to the regional technical standards applied, the national level of economic development attained as well as the local geological, hydrological and atmospheric conditions being in place would have a severely adverse effect upon the general availability of insurance cover. The highly complex field of environmental impairment liability insurance must be left to the liberal development along commercial principles and be free from artificially imposed rules and regulations.

\section{Final remarks}

The insurance industry is in the position and willing to perform its role within the transfer of risks from the entrepreneur to the insurance carrier.

However, in respect of the highly sensitive area of environmental impairment liability and its insurance such role can only be performed in an adequate manner and to the benefit of all parties in the long run, if the insurer can operate within a stable legal framework and within liberal boundaries set and kept by the legislator.

The European Union is presently in progress to define the environmentally orientated legal framework constituting the platform for the future. The Green Paper has demonstrated that the European Union has recognized the need to abolish the existing 'patchwork' of rules and regulations and instead to establish a 'system'. This general objective is to be qualified as positive approach to the complex situation being in place. Within the definition of alternative ways to solve the fundamental environmental problems faced the European Union has furthermore shown in the Green Paper that the design of such a 
system can be defined in line with the legal requirements for a workable liberal economy of which the insurance industry constitutes an important part.

It is now the task of the competent Authorities to set up this system in such a way that it will create a challenge and not constitute a nightmare for all concerned - among them also for the environmental impairment liability insurer.

\section{REFERENCES}

BREINING, Walter: Die Versicherbarkeit von Umwelthaftpflichrisiken, in: Haftpflichtrisiken in Industrie und gewerblicher Wirtschaft und Probleme ihrer Versicherung, S. 27ff., Karlsruhe, 1988

Comité Européen des Assurances: European Commission Green Paper on Remedying Environmental Damage, Insurers' Remarks, RC 048(09/93), Paris, 15 September 1993

Commission Green Paper on Remedying Environmental Damage, in: European Environmental Review, June 1993, pp. 12

Convention on Civil Liability for Damage resulting from Activities dangerous to the Environment, Council of Europe, 8 March 1993 (open for signature)

Directive on Civil Liability for Damage caused by Waste, COM (91) 219 final -SYN 217, 27 June 1991 (not enacted)

Directive on the Landfill of Waste, COM (91) 102 SYN 335, 23 April 1991 (not final, not enacted)

Directive on General Product Safety, 92/59 EEC, 29 June 1992

EC's Green Paper on Environmental Liability, in: European Environmental Review, January 1994, pp. 1

EC Green paper launched, in: World Insurance Report, March 26, 1993, p. 10

GOLDER, Stefan: 'Schillerndes' Subsidiaritätsprinzip in der EU, in: Neue Zürcher Zeitung, 26. Oktober 1994, Nr. 250, S. 25

Green Paper on Remedying Environmental Damage, Commission of the European Community, COM (93) 47 final, 14 May 1993

LUCIUS, Ralph René: Die Grenzen der Versicherbarkeit, Frankfurt a.M., 1979

International Chamber of Commerce: Environmental Liability and Financial Security, Position Paper, adopted in October 1993

NAPIER, Christoph: Payoung out for pollution, in: reactions, July 1993, pp. 19

SCHUBERT, Martin: Environmental Impairment Liability and Insurance in Europe. Where are we heading? Paper presented at the 4th World Insurance Conference in London, 1993

SPÜHLER, Jürg: Environmental Liability Risks - A Global View on Present Problems and their Assessing and Covering by Insurance, Paper presented at the Recycle ' 95 Environmental Technology - Global Forum \& Exposition, May 15-19, 1995 in Davos, Switzerland

Steps towards a draft directive, in: Environmental Liability Review, June 1995, p. 8

Technical Report: Environment (compiled by Cologne Re), in: Reinsurance, April 1994, pp. 2 